\title{
Special Issue on Intergroup Emotions: Introduction
}

\author{
Roger Giner-Sorolla \\ University of Kent \\ Diane M. Mackie \\ University of California, Santa Barbara
}

Eliot R. Smith

University of Indiana
IT is hard to imagine studying the psychology of intergroup relations without a theory of group-based emotions. The everyday language of social issues, after all, betrays the importance of emotion in both intergroup prejudice and intragroup cohesion: 'hate crime', 'Black pride', 'guilty liberals', 'homophobia', 'Islamophobia', 'angry White males', 'name and shame', and lest we forget the etymology of this last highly charged term, 'terrorism'. Yet it is only in the past 15 years that theory and research on the interface between emotions and groups has really taken off in social psychology. A look at current journals and conference programs leaves no doubt that group-based emotions are a vigorously studied topic today. Nevertheless, as with any rapidly advancing topic, there is obvious room for further expansion, consolidation, and creativity, and each of the eight articles we have chosen for this special issue illustrates this point admirably.

A quick look at the reference and introduction sections of these articles shows the widespread influence of two theoretical frameworks connecting emotions and groups. One of these, intergroup emotion theory (IET; Smith, 1993; Mackie, Devos, \& Smith, 2000; Mackie \& Smith, 2002), addresses how, when and why individuals will feel specific emotions in reaction to events that bear upon social groups. IET combines insights from appraisal theory and social identity theory. Specifically, it uses the concept of the social self as a bridge between events seen as relevant to a group and emotions felt by an individual who identifies with the group. In an appraisal interpretation, we feel angry at an individual because we see him or her as being the agent of a bad outcome for our own self. Likewise, in the IET interpretation, we can feel angry at another group that we see as the agent of a bad outcome for our own group. This occurs because, in the process of social identification, we invest a portion of our self in the group (Smith \& Henry, 1996). Moreover, different specific emotions have implications for adaptive action beyond their positive or negative valence (Frijda, 1986). Therefore, research derived from IET can use individual appraisal theories to predict what perceptions will lead to anger and attack, fear and withdrawal, or guilt and compensation between groups-to name only

\footnotetext{
$\overline{\text { Author's note }}$

Address correspondence to Roger Giner-

Sorolla, Centre for the Study of Group

Processes, Department of Psychology,

University of Kent, Canterbury,

Kent CT2 7NP, UK [email: rsg@kent.ac.uk]
} 
three of the dozens of meaningfully different emotions.

The other theoretical framework concerns itself with the association of emotions with the ingroup versus other groups. Specifically, the theory of subjective essentialism sees bias in the attribution of emotions to other groups as one implicit marker of their infrahumanization (Leyens et al., 2000). Complex, secondary emotions such as guilt, pride, and nostalgia are seen as uniquely human. Group members also show a well-replicated tendency to see secondary emotions as more characteristic of the ingroup than the outgroup, subjectively denying outgroup members a fully human essence. Thus, while IET emphasizes appraisal-generated emotions felt by groups toward other groups, the theory of infrahumanization emphasizes bias in ascribing emotions to other groups, motivated by a reluctance to acknowledge their members as essentially like one's own group.

Although we selected the eight research articles in this issue on their considerable individual merits, they do show some interesting shared sub-themes that work to expand one or both of these theoretical ideas. First, several articles address a specific concern that often arises when applying intergroup emotion theory to selfcritical emotions such as guilt and shame. A tendency has been observed for individuals high in group identification to show lesser, not greater, amounts of self-critical affect when confronted with blameworthy group actions (Doosje, Branscombe, Spears, \& Manstead 1998). A common explanation of this phenomenon is that individuals are motivated to defend against emotions that are painful and threatening to their collective esteem. Three of the articles in this issue examine processes that might serve as such defenses.

Mallett and Swim test a number of proposed determinants of intergroup guilt against each other simultaneously across a number of different social groups, and find an overall tendency for justifications of intergroup differences to reduce the effects of perceived collective responsibility in predicting guilt. Just as intriguing is the failure of these justifications to reduce the impact of the perceived importance of the group's own advantage on guilt; in fact, justifications increased with increasing importance. This suggests that strong perceived inequalities may create seemingly irrational feelings of guilt, even when responsibility is not acknowledged and justifications for inequality are accepted.

The article by Gill and Andreychik looks at a concept, ultimately inspired by attribution theory, that might be seen as the converse of Mallett and Swim's justifications. External social explanations, in these studies, are beliefs that endorse situational causes for the different status of an outgroup. Independently of a number of other plausible influences, including internal social explanations, external explanations of group differences predicted greater guilt among Whites toward Blacks in the United States. Here, it is not so much the justifiability of inequality that accompanies lower guilt, but its unjustifiability that accompanies higher guilt. This offers both a parallel and an interesting contrast to the emerging literature on justifications of prejudice.

The collective contribution of Zebel, Pennekamp, van Zomeren, Doosje, van Kleef, Vliek, and van der Schalk investigates emotions linked to the Netherlands' colonial past using an innovative method based on family history. Family is a connection to the collective past that is harder to deny than mere nationality. While these studies' Dutch participants showed little collective guilt for colonial injustices to which they only had a national link, they showed more guilt when they believed their family to have been involved. When group members are faced with past atrocities that defy easy justification, this finding points to one way to overcome the historical denial that forms a second kind of defense against collective guilt.

This last article also illustrates a second theme that emerges in this issue: novel approaches to group identification's role in determining the strength of intergroup feelings. Crisp, Heuston, Farr, and Turner offer evidence that the extent of identification with a sports team can affect not just the intensity of group-based 
emotions, as previously shown, but the qualitative nature of such emotions. This reminds us that identification is not just a volume knob that cranks up the strength of an individual's groupbased emotions, but can determine whether the individual sees him or herself as the protagonist rather than a mere spectator in the group's dramas. In appraisal theories of emotion, self versus other involvement is often a crucial appraisal distinguishing between pairs of very different emotion types. The approach of Crisp and co-authors is thus ripe for application to emotions beyond their initial focus on anger and sadness.

Pennekamp, Doosje, Zebel, and Fischer find it necessary to go beyond a simple model of identification in studying the determinants of collective anger among the Dutch Surinamese minority and among women. Here, too, attitudes toward the collective past show their importance. In particular, the perceived relevance of the past to present-day issues predicts collective anger, mediating the effects of identification. Together with the Zebel et al. studies in this issue, these findings make a compelling case that identity extends across social time as well as social space, and that both dimensions of identity need to be measured when predicting reactions to the historical past.

A third theme, shared by two articles, examines infrahumanization through denial of secondary emotions as a barrier to positive intergroup outcomes. The study reported by Cuddy, Rock, and Norton takes infrahumanization as its major focus. It assessed public reactions shortly after the devastating and ethnically divisive impact of Hurricane Katrina, and demonstrates that infrahumanization of outgroup members in that context accompanies a lower willingness to help them. No less divisive is the ongoing religious violence in Northern Ireland. Within this setting, the studies reported by Tam, Hewstone, Cairns, Tausch, Maio, and Kenworthy deal with infrahumanization as a barrier to forgiveness in the wider context of intergroup contact and personally felt anger. This article has a particularly welcome integration of perceived and felt emotions, showing the two factors to have independent effects on forgiveness. At the same time, we should not ignore the more subtle interplay shown by Cuddy and colleagues between the personal emotion of empathy and perceived secondary emotions. As they point out, their results suggest that people help an outgroup only when they spontaneously empathize with the outgroup members' uniquely human sentiments. Exploring the relations between personal emotions and perceived outgroup emotions looks to be a particularly promising direction in this area of research.

The article by Tapias, Glaser, Keltner, Vasquez, and Wickens contrasts the emotions of anger and disgust in a way that bears on a quite different theoretical perspective relevant to intergroup psychology—namely, attitude theory. Many appraisal theories focus on emotion as an adaptive response to challenges and opportunities as they arise. At the same time, emotional reactions can inscribe themselves in memory as schematic associations with an attitude object, forming an affective component of attitude that informs future reactions. Tapias and colleagues provide a demonstration of this latter point. They show that the incidental mention of outgroups typically associated with either anger or disgust can prime the experience of that specific emotion, and that conversely, chronic susceptibility to anger or disgust goes with more intense attitudes toward the relevant outgroups. This finding reminds us that emotional associations can be self-sustaining, arising from sources other than adaptation to the current situation. It also tightly links group-based emotions to individual-level emotions by showing that individual differences in susceptibility have similar effects at both levels.

In conclusion, we would first like to thank our authors, all of whom have contributed research of great creativity and rigor. The anonymous reviewers and consulting editors who contributed so many insights to the editorial process, and impressed us with their diligence and promptness, also deserve their share of praise. Our thanks for making this issue possible in the first place go to the editorial board of GPIR, Dominic Abrams, and Mike Hogg. Finally, we are extremely grateful 
for the efforts of the GPIR editorial assistant, Katerina Tasiopoulou, without whose talent and dedication this project would have been far more difficult and far less organized.

\section{References}

Doosje, B., Branscombe, N. R., Spears, R., \& Manstead, A. S. R. (1998). Guilty by association: When one's group has a negative history. Journal of Personality and Social Psychology, 75, 872-886.

Frijda, N. H. (1986). The emotions. Cambridge, UK: Cambridge University Press.

Leyens, J. P., Paladino, P. M., Rodriguez-Torres, R., Vaes, J., Demoulin, S., Rodriguez-Perez, A. et al. (2000). The emotional side of prejudice: The attribution of secondary emotions to ingroups and outgroups. Personality and Social Psychology Review, 4, 186-197.

Mackie, D. M., Devos, T., \& Smith, E. R. (2000). Intergroup emotions: Explaining offensive action tendencies in an intergroup context. Journal of Personality and Social Psychology, 79, 602-616.

Mackie, D. M., \& Smith, E. R. (2002). Beyond prejudice: Moving from positive and negative evaluations to differentiated reactions to social groups. In D. M. Mackie \& E. R. Smith (Eds.), From prejudice to intergroup emotions: Differentiated reactions to social groups (pp. 1-12). New York: Psychology Press.

Smith, E. R. (1993). Social identity and social emotions: Toward new conceptualizations of prejudice. In D. M. Mackie \& D. L. Hamilton (Eds.), Affect, cognition, and stereotyping: Interactive processes in group perception (pp. 297-315).

Smith, E. R., \& Henry, S. (1996). An in-group becomes part of the self: Response time evidence. Personality and Social Psychology Bulletin, 22, 635-642.

\section{Biographical notes}

ROGER GINER-SOROLLA has been on the permanent faculty of the Department of Psychology at the University of Kent at Canterbury since 2001, where he is now Senior Lecturer. He received his PhD from New York University and completed an NIMH post-doctoral fellowship at the University of Virginia. His research interests include affective attitudes and the role of four specific emotions - anger, disgust, guilt, and shame - in moral judgments, self-control, and intergroup prejudice. In 2004, together with Rupert Brown, he organized a European Science Foundation workshop on intergroup emotions at Kent, which led to the initial proposal for this special issue of Group Processes $\mathcal{E}$ Intergroup Relations.

DIANE M. MACKIE is professor of psychology and communication at the University of California, Santa Barbara. She received her PhD from Princeton University. Her research interests include the affective antecedents and consequences of intergroup relations, as well as social influence and persuasion. With Eliot Smith, she is co-editor of From Prejudice to Intergroup Emotions (Psychology Press, 2002).

ELIOT R. SMITH is professor in the Department of Psychological and Brain Sciences at Indiana University, Bloomington, and he also holds a Special Chair at the Free University, Amsterdam. His PhD is from Harvard University. His work centers on the role of emotions in prejudice and intergroup behavior, and socially situated cognition. He recently completed a term as editor of Personality and Social Psychology Review. 